\title{
Investigation of a Coolant Mixing Phenomena within the Reactor Pressure Vessel of a VVER-1000 Reactor with Different Simulation Tools
}

\author{
V. Sánchez, ${ }^{1}$ W. Jaeger, ${ }^{1}$ M. Boettcher, ${ }^{1}$ and B. Truong ${ }^{2}$ \\ ${ }^{1}$ Forschungzentrum Karlsruhe GmbH (FZK), Institute of Neutron Physics and Reactor Technology (INR), \\ Hermann-von-Helmholtz-Platz 1, 76344 Eggenstein-Leopoldshafen, Germany \\ ${ }^{2}$ Massaschusetts Institute of Technology, 77 Massachusetts Avenue, 24-215, Cambridge, MA 02139-4307, USA \\ Correspondence should be addressed to V. Sánchez, victor.sanchez@inr.fzk.de \\ Received 19 May 2009; Accepted 4 October 2009 \\ Academic Editor: Dubravko Pevec
}

Copyright () 2010 V. Sánchez et al. This is an open access article distributed under the Creative Commons Attribution License, which permits unrestricted use, distribution, and reproduction in any medium, provided the original work is properly cited.

\begin{abstract}
The Institute of Neutron Physics and Reactor Technology (INR) is involved in the qualification of coupled codes for reactor safety evaluations, aiming to improve their prediction capability and acceptability. In the frame of the VVER-1000 Coolant Transient Benchmark Phase 1, RELAP5/PARCS has been extensively assessed. Phase 2 of this benchmark was focused on both multidimensional thermal hydraulic phenomena and core physics. Plant data will be used to qualify the 3D models of TRACE and RELAP5/CFX, which were coupled for this purpose. The developed multidimensional models of the VVER-1000 reactor pressure vessel (RPV) as well as the performed calculations will be described in detail. The predicted results are in good agreement with experimental data. It was demonstrated that the chosen 3D nodalization of the RPV is adequate for the description of the coolant mixing phenomena in a VVER-1000 reactor. Even though only a 3D coarse nodalization is used in TRACE, the integral results are comparable to those obtained by RELAP5/CFX.
\end{abstract}

\section{Introduction}

The qualification of thermal hydraulic system codes is an important prerequisite for the use of best-estimate codes to assess the safety features of nuclear power plants. In the last years, many best-estimate codes were improved by the implementation of three-dimensional thermal hydraulic (3D) models, at least for the reactor pressure vessel. Good examples of such codes are RELAP5-3D [1], TRAC-B/P [2], CATHARE-3D [3], ATHLET-FLUBOX [4], and TRACE [5]. In TRACE, a 3D vessel model in both cartesian and cylindrical geometry is available. Since these system codes are coupled to 3D neutron kinetic codes, powerful multidimensional tools like RELAP5/NESTLE, CATHARE/CRONOS2, and TRACE/PARCS arise which can be used to analyze transients with strong, nonuniform power perturbations.

The main goal of this analysis is to evaluate the prediction capabilities of the multidimensional thermal hydraulic models of TRACE by comparing calculated results with both experimental plant data and with an RELAP5/CFX-coupled simulation using a rather coarse azimuthal TRACE nodalization since it is the first attempt to validate the $3 \mathrm{D}$ vessel model. The test data are related to the coolant mixing phenomena within the RPV of a VVER-1000 reactor, which was distributed by the VVER-1000 Coolant Transient Phase 2 benchmark team [6]. It is an excellent opportunity to qualify the 3D models of TRACE. These investigations are restricted to the first exercise of the benchmark phase.

One option is to describe the coolant mixing by 1D system codes, where the downcomer is subdivided into several parallel channels that are connected to each other at each axial elevation by cross flow. In such approach, the appropriate form loss coefficients at the cross connections are needed. However, their derivations are not trivial and depend on the user's experience and engineering judgment. On the contrary, the 3D models of codes like TRACE solve the fluid dynamics equations in three directions and no additional effort is necessary to obtain the right cross flow among the azimuthal sectors or rings. In addition, the CPU time of coarse mesh 3D thermal hydraulic models increases with 
TABLE 1: Main parameter of the VVER-1000 core.

\begin{tabular}{lc}
\hline Parameter & Value \\
\hline Pellet diameter, mm & 7.56 \\
Central void diameter, mm & 1.4 \\
Clad diameter (outside), mm & 9.1 \\
Clad wall thickness, mm & 0.69 \\
Fuel rod total length, mm & 3837 \\
Fuel rod active length (cold state), mm & 3530 \\
Fuel rod active length (hot state), mm & 3550 \\
Fuel rod pitch, mm & 12.75 \\
Fuel rod grid & Triangular \\
Number of guide tubes & 18 \\
Guide tube diameter (outside), mm & 12.6 \\
Guide tube diameter (inside), mm & 11.0 \\
Number of fuel pins & 312 \\
Number of water rods/assembly & 1 \\
Water rod diameter (outside), mm & 11.2 \\
Water rod diameter (inside), mm & 9.6 \\
FA wrench size, mm & 234 \\
FA pitch, mm & 236 \\
\hline
\end{tabular}

the increase of the $3 \mathrm{D}$ nodes, that is, there is a limitation for the refinement of the 3D domain.

The development of coarse mesh 3D thermal hydraulic models for a complete reactor pressure vessel is very challenging since a proper strategy needs to be developed for the discretization of the computational domain in axial levels, radial rings, and azimuthal sectors. To do so, the constructive peculiarities of the main flow paths such as the downcomer, lower plenum, core, and upper plenum must be taken into account.

The modeling efforts for this analysis will be described in the following chapters. The test conditions and measured data as well as the results obtained with the different thermal hydraulic codes will be presented and discussed hereafter.

\section{Peculiarities of the VVER-1000 Reactor}

The VVER-1000 is a Russian type pressurized water reactor (PWR), operated at around 15.5 MPa. It is a four loop plant with horizontal steam generators (SGs). The fuel pins are arranged in hexagonal fuel assemblies (FAs) with a central hole instead of square FA found in most western type reactors. In the benchmark specifications [6] geometrical specifications and operational conditions are given so that the development of the models for the computer simulations is possible. In Table 1, some important data of the VVER1000 plant are summarized [6].

Regarding the foreseen investigations, it has to be noted that the constructive peculiarities of the RPV in-vessel structures are an additional challenge for the development of a detailed 3D model, especially for codes like CFX [7] and TRACE. Figure 1 shows the constructive peculiarities of the lower and the upper plenum of the VVER-1000 RPV, which is more complex than that of Western type PWR.
The description of the relevant flow patterns within the RPV needs special considerations regarding the axial, radial, and azimuthal direction. Since the envisaged investigations dealing with asymmetrical heat-up of the primary system due to the perturbation in one of the four loops, it is important to note that in the case of the VVER-1000 reactor, the four loops are not symmetrically arranged, has indicated in Figure 2. This peculiarity will influence the multidimensional flow conditions and it represents an additional challenge for the model developers.

The constructive design of the VVER-1000 RPV internals represents a real challenge for the development of a 3D RPV model. The most challenging aspects are summarized as follows:

(1) lower plenum: radial core barrel elliptical bottom, support columns (hallow with perforation of different size),

(2) core design: fuel assemblies and fuel pin arrangement,

(3) upper grid plate with upper perforated fuel assembly head,

(4) upper plenum: inner perforated cylinder (lower part: conic) and outer perforated cylinder.

In Figure 3, the complex flow path along the lower plenum is depicted. There, the coolant has to pass first through the 163 holes of the core barrel elliptical bottom. Then, it flows upwards, along the support columns, and enters through the perforated support columns upper part. Finally, it flows through the lower core support plate into the fuel assembly.

A further challenge is the fuel pin arrangement in the core regarding the azimuthal and radial nodalization. Assumptions and engineering judgment have to be made to estimate the main thermal hydraulic parameters at the cell faces; see Figure 4. Especially the evaluation of the following input deck parameters is crucial: (1) cell volume liquid-tosolid ratio, (2) flow area fraction, (3) hydraulic diameter, and (4) additional form loss coefficient. Furthermore, the peculiarities of the upper end of the fuel assembly and the upper grid plate, Figure 5, result in complicated flow path through the perforated, conical part of the fuel assembly head, and finally through the upper core support plate. The upper plenum is characterized by two concentric cylinders with perforations, through which the coolant has to pass, shown in Figure 6. The presence of the guide tubes makes the flow more complex. The coolant, leaving the core, flows through the perforated part of the inner ring and then through the perforated core barrel.

\section{Short Description of the Numerical Tools}

For the investigation of the coolant mixing that occurred during the heat-up test at the Kozloduy nuclear power plant, the system code TRACE and the offline coupled RELAP5/CFX are used. TRACE [5] (TRAC/RELAP Advanced Computational Engine) is being developed by Los Alamos National Laboratory (LANL) and the Pennsylvania State University. TRACE is a multidimensional, two-phase 


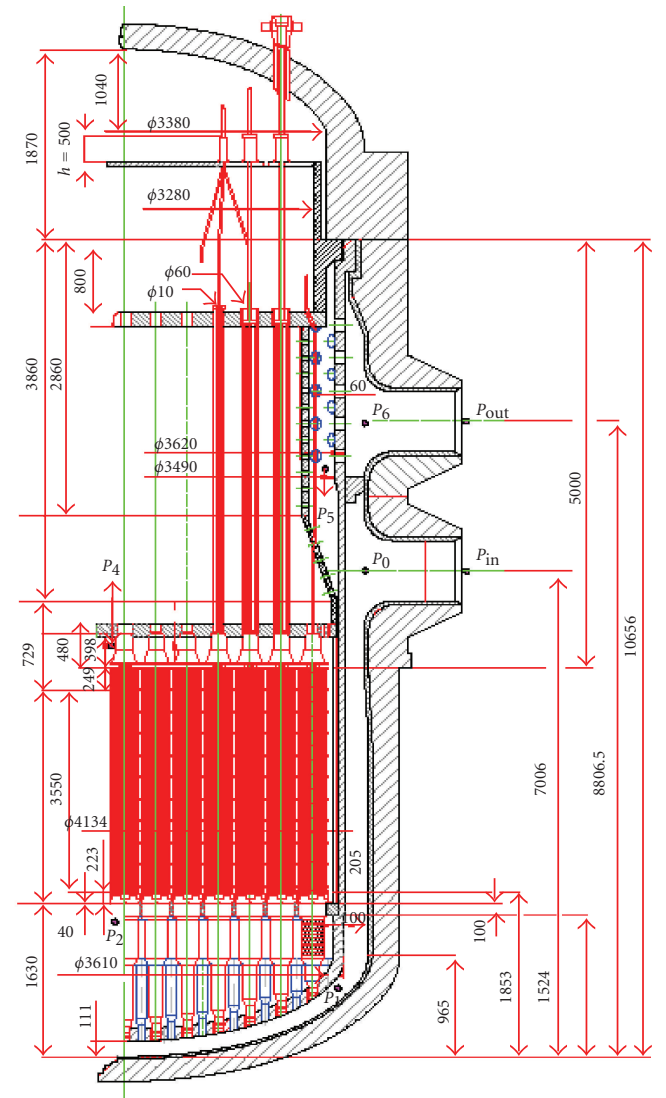

Figure 1: The RPV of the VVER-1000 reactor with the constructive peculiarities.

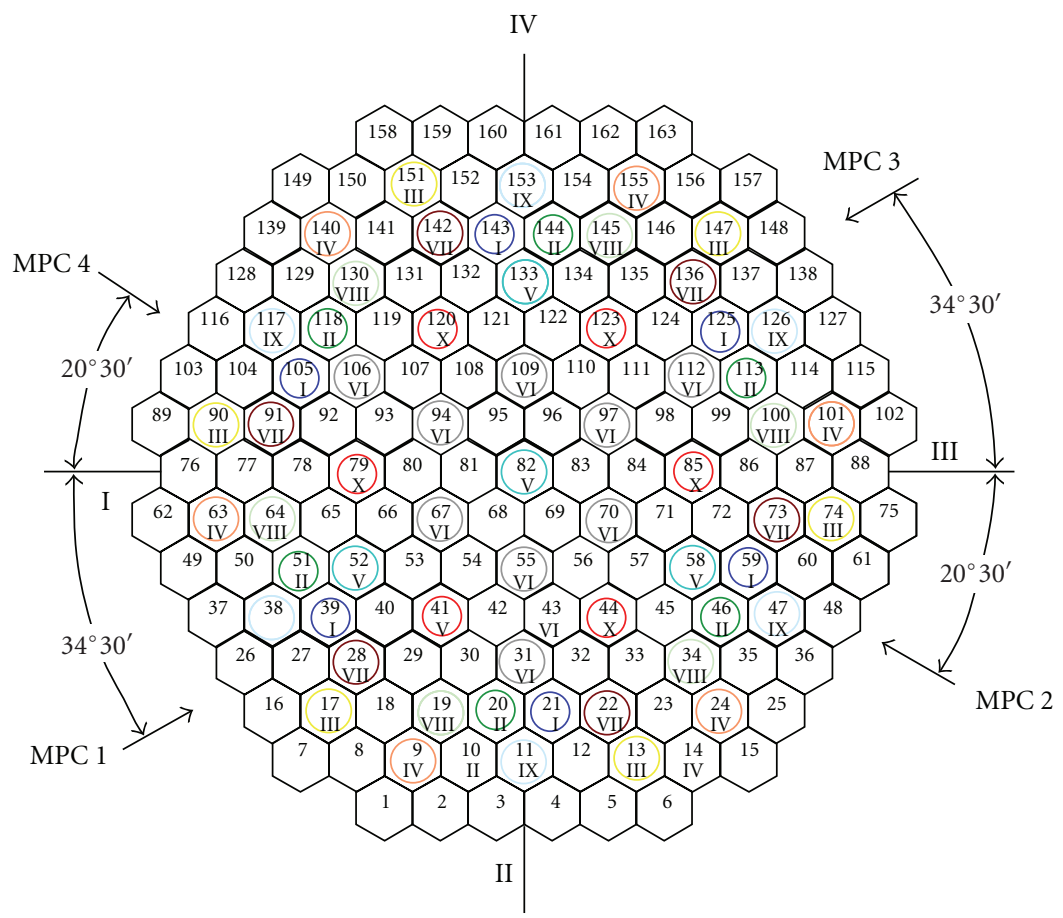

FIGURE 2: The asymmetrical arrangement of the loops (I, II, III, and IV) related to the core. 


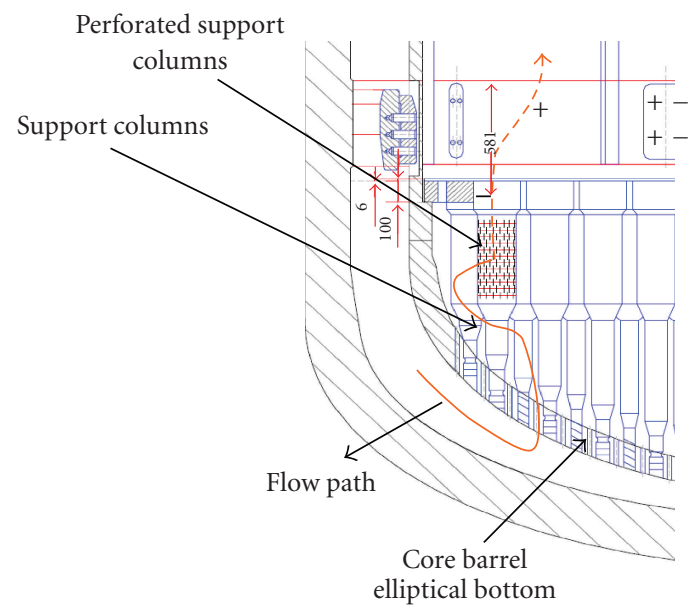

Figure 3: Constructive details of the lower plenum and complex flow path.

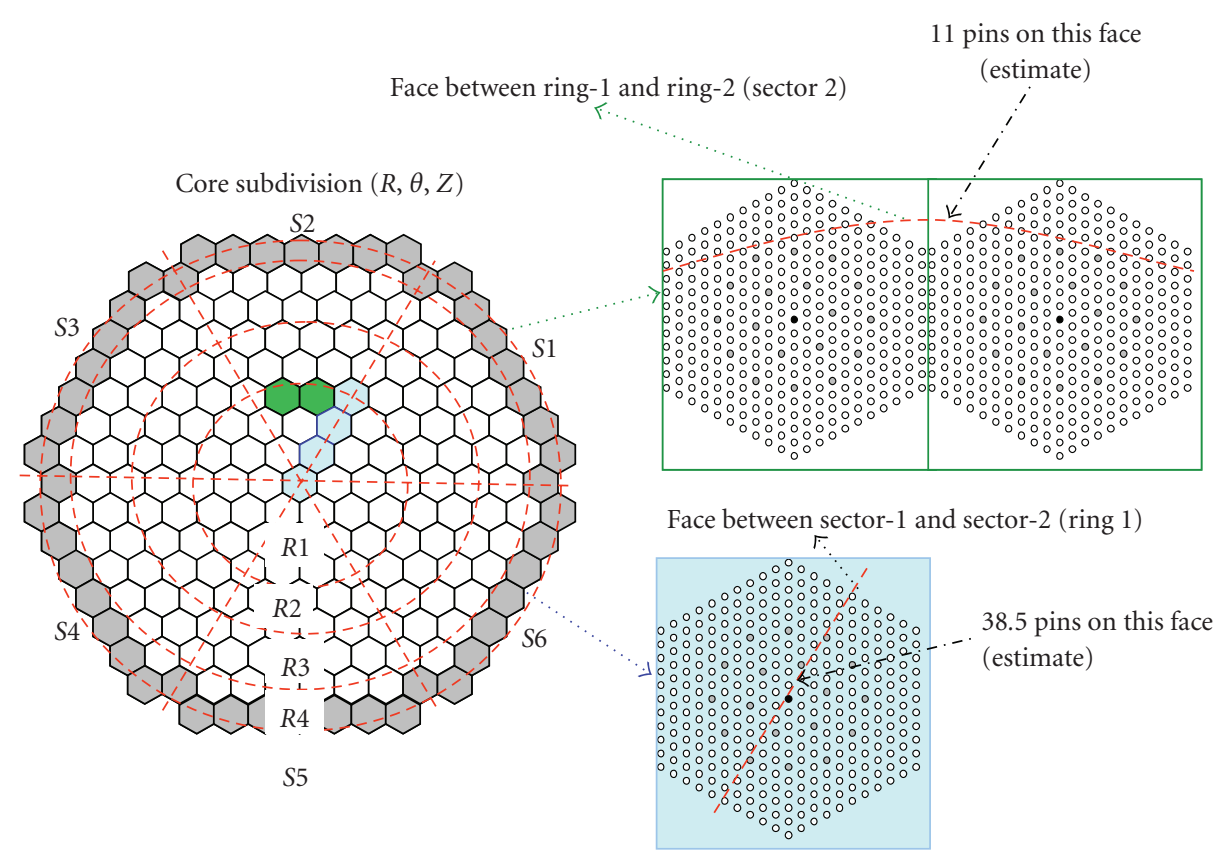

FIGURE 4: Pin arrangement regarding the nodalisation lines in radial and azimuthal direction.

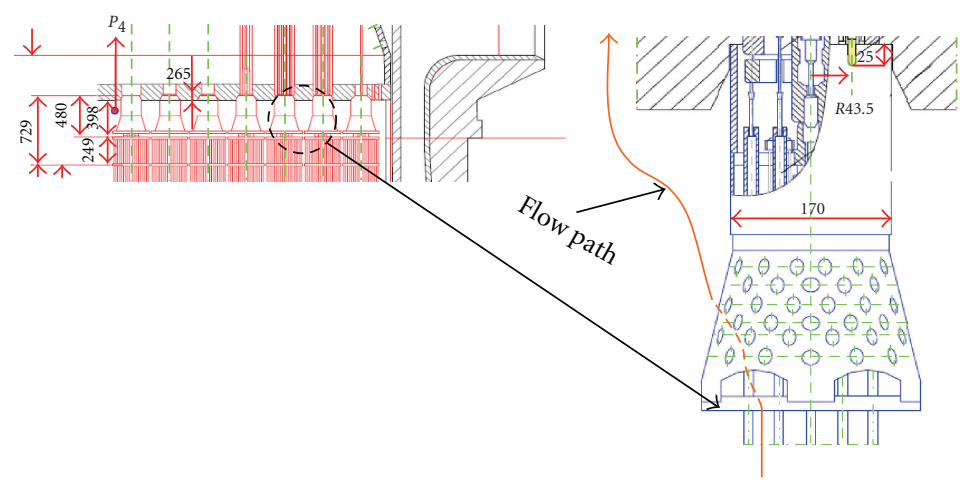

FIgURE 5: Flow conditions at the fuel assembly head and upper grid plate. 


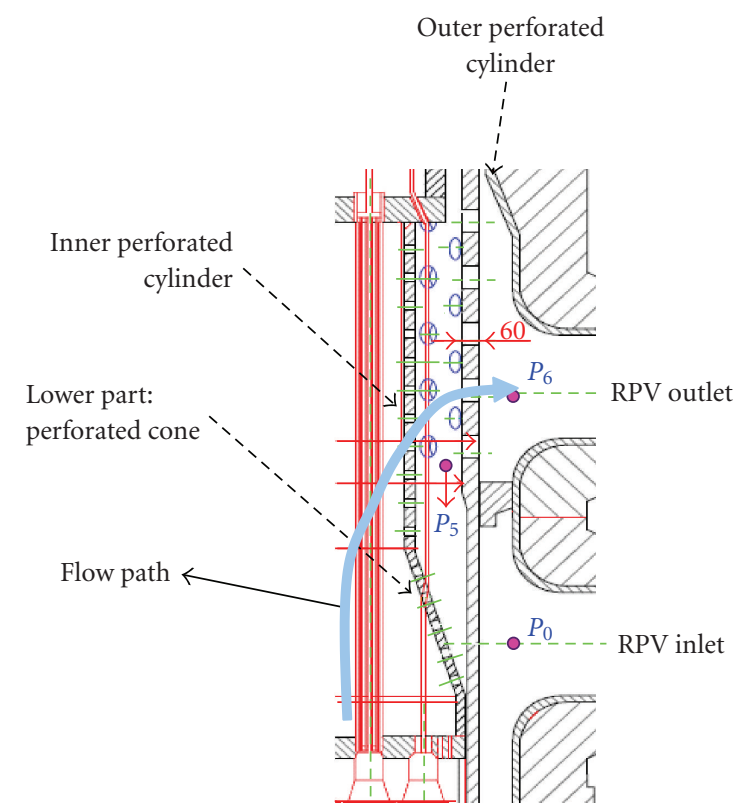

FIGURE 6: Vertical arrangement of the VVER-1000 primary components.

flow system code, developed to simulate any kind of operational events, transients, and design basis accidents of both boiling water reactor (BWR) and PWR. The component VESSEL allows the $3 \mathrm{D}$ simulation of the flow in the reactor pressure vessel. In addition, different working fluids such as gas and liquid metals are included in TRACE so that it can be also used to assess the safety features of innovative reactors such as GEN IV reactors. The in-build point kinetics model, based on the Kaganove-approach, is extended by the coupling or direct incorporation of the three dimensional core reactor simulation tool PARCS [8]. Thanks to the coupling of RELAP5 and TRACE to PARCS, a powerful system is created that is appropriate for the simulation of transients and accident scenarios where a strong power perturbation within the core exists and where the thermal hydraulic core behavior is strongly related to the core neutronic processes (e.g., MSLB scenarios, ATWS, boron dilution). CFX [7] is a commercial CFD tool widely used to simulate $3 \mathrm{D}$ flow in complex geometries. Its application in the nuclear reactor safety is rapidly increasing, especially for single phase flow situations.

\section{Thermal Hydraulic Models of the Reactor Pressure Vessel}

4.1. The 3D TRACE Model of the Reactor Pressure Vessel. A detailed 3D model of the RPV of the VVER-1000 reactor representing the most relevant internals was developed for TRACE [9]. Before that, a complete model for the VVER1000 reactor with RELAP5/PARCS was developed [10]. It includes, for example, the downcomer, lower plenum, core, core outlet, upper plenum, and RPV inlet and outlet pipes. A detailed description of this model can be read in [9]. The 3D VESSEL component of TRACE was used for the representation of the RPV. According to this, the whole
RPV is subdivided in 30 axial levels, six radial rings and six azimuthal sectors (Figures 7 and 8 ). The sizes of the respective nodes depend on the existing flow conditions along the main flow paths within the RPV determined by the constructive peculiarities of the RPV internals. From the 30 axial levels of the RPV, 10 axial nodes belong to the core region while two belong to the lower and upper axial reflector. The azimuthal sectors (S1 to S6) were defined in a way that the cold legs are connected to sector 4 (cold leg 1), sector 6 (cold leg 2 ) sector 1 (cold leg 3 ), and sector 3 (cold leg 3).

Figure 9 shows radial nodalization of the RPV into 6 rings, 3 of which are for the core. For each of the $3 \mathrm{D}$ volume elements, the main thermal hydraulic parameters for each direction such as hydraulic diameter, flow area, heated diameter, and form loss coefficients are derived from the detailed plant data. To catch the asymmetrical coolant mixing expected to occur mainly in the downcomer and lower/upper plenum a rather fine nodalization of the RPV in azimuthal and radial direction is needed. One has to keep in mind that the finer nodalization leads to a higher CPU time. A reasonable compromise between accuracy and CPU cost is here mandatory. In Figure 8, the radial and azimuthal nodalization of the core is shown. In developing the $3 \mathrm{D}$ model using the VESSEL component the following aspects had to be kept in mind.

(i) Make use of geometrical symmetry $(R, \theta, Z)$.

(ii) Select the size of cells (radial, axial, angular) as small as necessary (based on underlying physics).

(iii) Consider the details of flow paths as much as necessary.

(iv) Otherwise the 3D model may become unnecessary complex. 


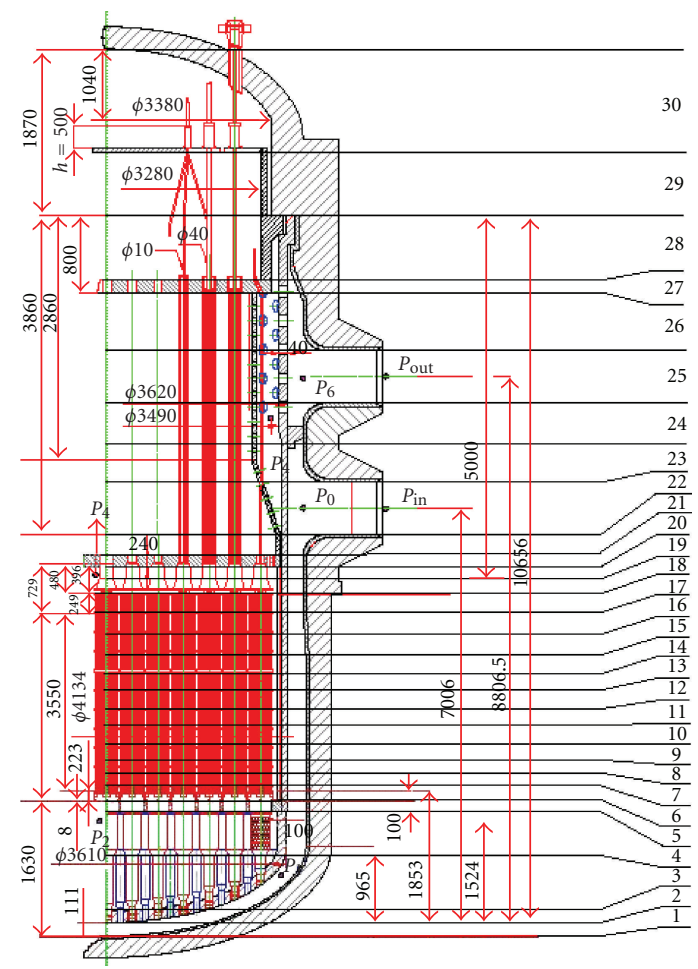

FIGURE 7: TRACE axial nodalization of the RPV.

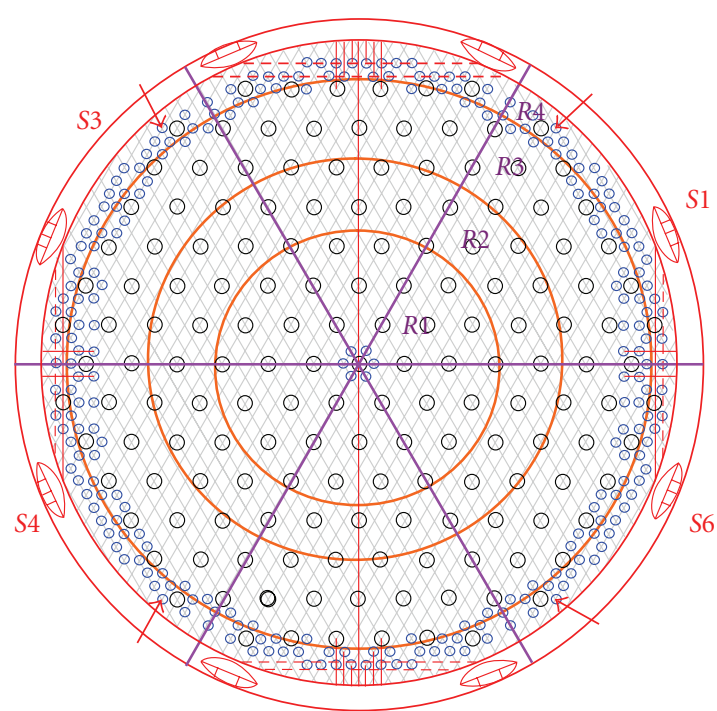

FIGURE 8: TRACE radial and azimuthal subdivision of the core.

The complete TRACE model as represented by SNAP (preand postprocessor) is shown in Figure 10. Part of the hot and cold legs, as well as the mass source and sinks, is represented with PIPE, FILL, and BREAK components. They are necessary to define the initial and boundary conditions of the problem being investigated. These boundary conditions are coolant temperature and mass flow rate (FILL) and system pressure (BREAK).
4.2. Combined 1D RELAP5 and CFX Model. Detailed models of the RPV, including the core, were developed for RELAP5 [11] and CFX [12]. Since the coolant mixing experiment is almost a thermal hydraulic problem with very weak reactivity feedbacks, it represents a unique opportunity for the simulation of the RPV and core behavior using a combination of CFD and system codes. 


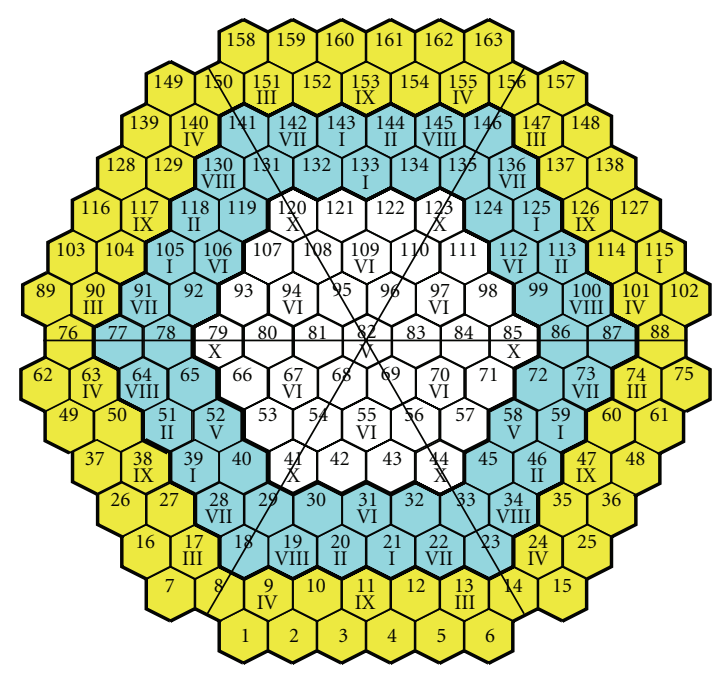

(a)

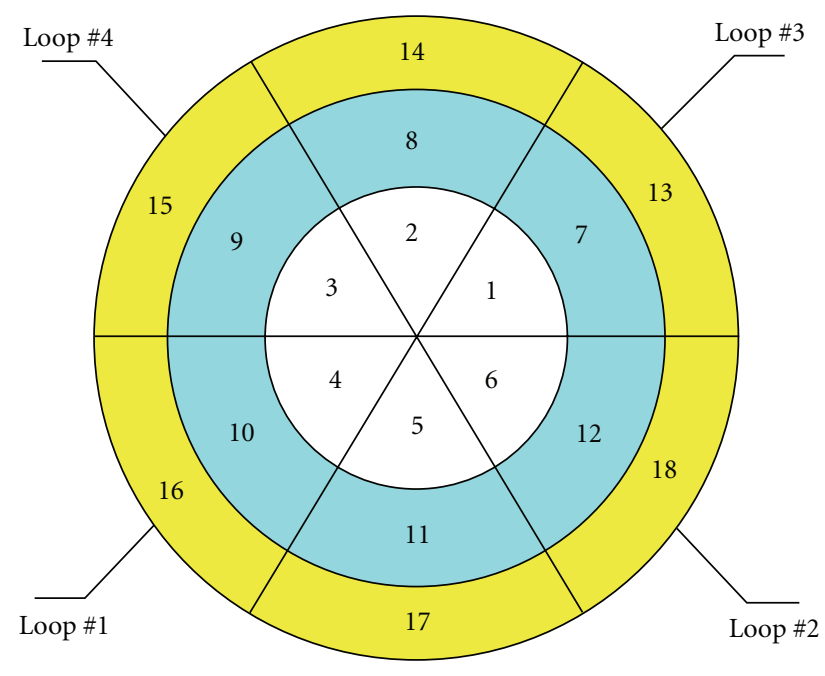

(b)

FIGURE 9: TRACE Nodalization of the core and relative position of the cold/hot legs.

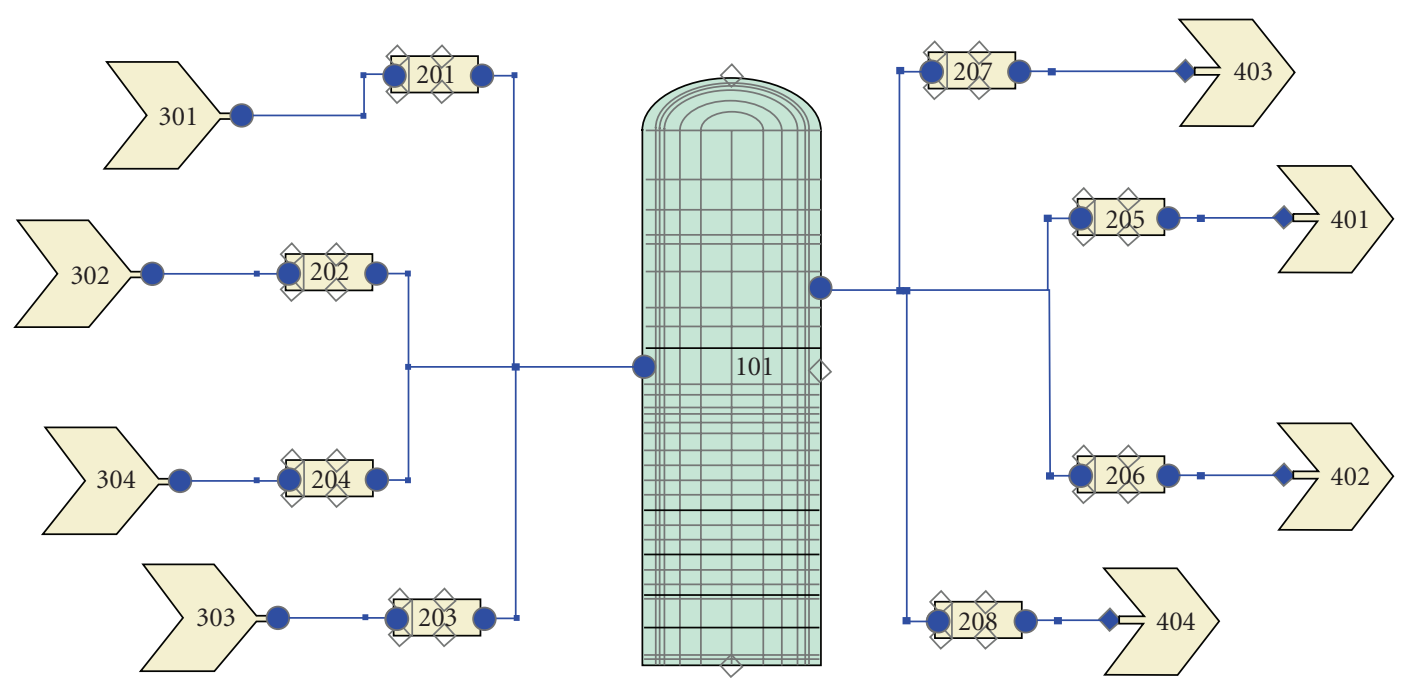

FIgUre 10: TRACE 3D Nodalization of the RPV with cold/hot legs.

All important RPV volumes, where coolant mixing is expected to occur such as downcomer and lower plenum till the core entrance, are simulated with CFX-5 (Figure 12). The core and the upper plenum, including the RPV outlets, are described by RELAP5 volumes (Figure 11). In this off-line coupling of CFX with RELAP, the data exchange between both models is realized at the core entrance, that is, at the inlet of each fuel assembly by time dependent boundary conditions (coolant temperature, mass flow rate and pressure). In the RELAP5 model, the core is represented by 164 parallel channels ( 163 represent FAs, 1 represents the bypass) together with their corresponding heat structures. Axially, the core region is divided in 10 axial levels and two additional more for the lower and upper axial reflector region. The core outlet and the upper plenum are represented by six equal sized sectors, modeled as parallel channels.
Sector 1 (vol 860), sector 2 (vol 861), and sector 3 (vol 862) belong to the "affected" core half and the other three sectors (vol 863, vol 864, and vol 865) to the "unaffected" core half. The RPV head is represented by single volumes (vol 870 and vol 880).

The CFD domain is represented by a detailed CFX-5 model [12] of the downcomer and lower plenum including all the constructive details of the complicated flow paths. A detailed description of this model is given in [12] (see Figure 12).

This CFX model is part of a complete CFX model of the RPV, including the core and upper plenum, that was developed for the V1000-CT-2 benchmark [12].

The coupling of RELAP5 and CFX presented here is an offline coupling realized for this specific problem. It can be improved by the development of a versatile interface module 


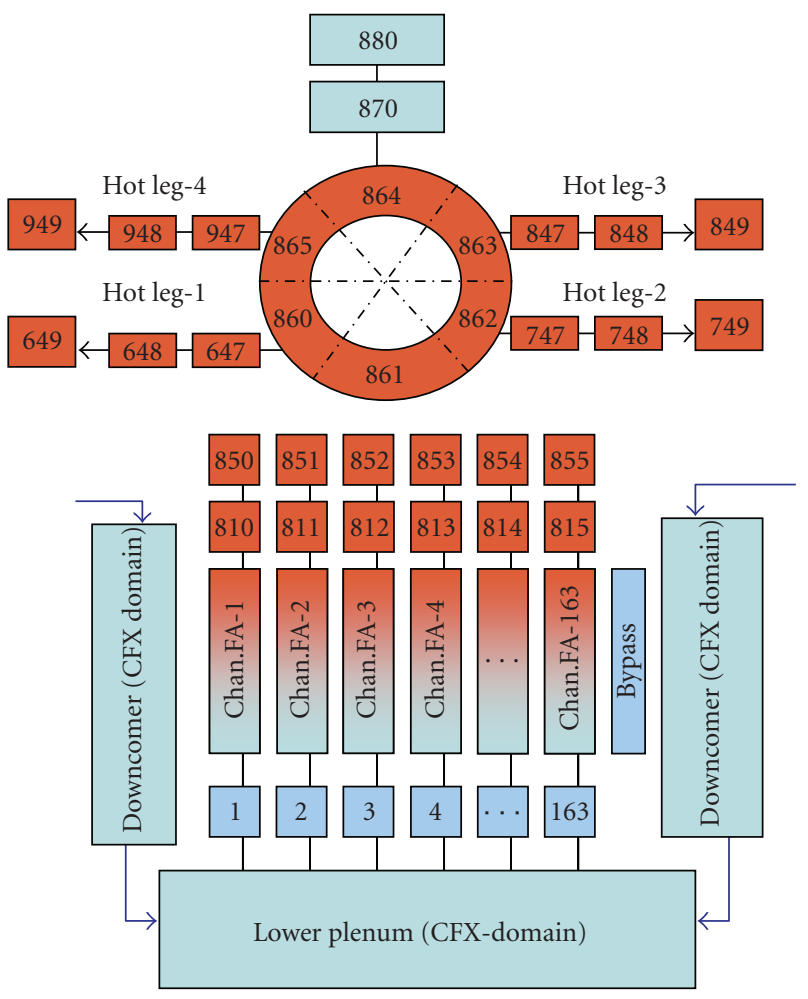

Figure 11: Sketch of the RPV Model with the CFX and RELAP5 domain.

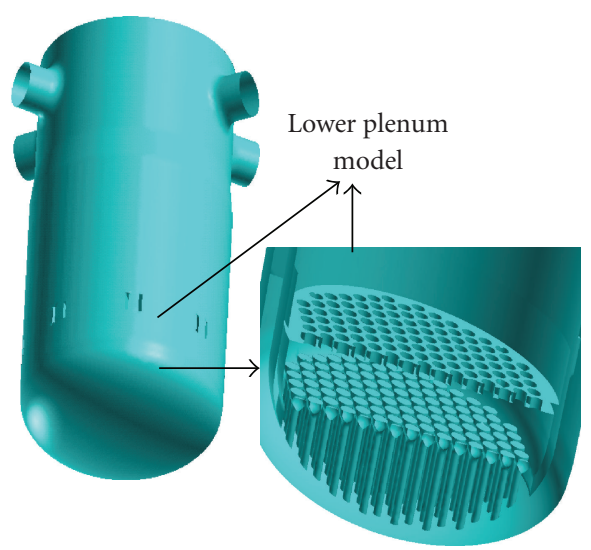

Figure 12: Detailed CFX-5 model of the downcomer and upper plenum of the RPV.

that allows more universal use of these codes to investigate combined 3D and 1D thermal-hydraulic process within the RPV of light water reactors. In the CFX, the constructive details of the lower plenum are treated as porous media mainly. This can be enhanced by a direct resolution of the constructive peculiarities of the lower plenum structures resulting in an increase of the number of cells, too.

\section{Simulation of the Heat-Up Experiment}

\subsection{Short Description of the Experiment}

5.1.1. Pretest Phase. Before the test, the nuclear power plant Kozloduy was operated at around $9.36 \%$ of the nominal power, that is, $281 \mathrm{MWth}$, with all main coolant pumps running. The main operational parameters are summarized in Table 2, together with the measurement accuracy. On the secondary side all steam generators were available. The core was loaded with fresh fuel, that is, at the beginning of cycle conditions (BOC) with a core-averaged exposure of 0.4 effective full power days (EFPDs) and a boron concentration of $7.2 \mathrm{~g} / \mathrm{kg}$. The positions of the control rod groups were as follows: groups \#9 and \#10 are fully inserted; groups \#1-\#7 are fully withdrawn; the regulating rod group \#8 was about $84 \%$ withdrawn from the bottom of the core. The coolant temperature at core inlet was $20 \mathrm{~K}$ lower that the one at nominal conditions. Finally the steam generator levels were as high as the ones at nominal conditions. The main steam 
TABLE 2: Main parameters of the four loops before the test.

\begin{tabular}{lcc}
\hline Parameter & Initial state & Accuracy \\
\hline Thermal power, MW & 281 & \pm 60 \\
Pressure above core, MPa & 15.593 & \pm 0.300 \\
Pressure drop over RPV, MPa & 0.418 & \pm 0.043 \\
Coolant temperature at core inlet \#1, K & 541.75 & \pm 1.50 \\
Coolant temperature at core inlet \#2, K & 541.85 & \pm 1.50 \\
Coolant temperature at core inlet \#3, K & 541.75 & \pm 1.50 \\
Coolant temperature at core inlet \#4, K & 541.75 & \pm 1.50 \\
Coolant temperature at core outlet \#1, K & 545.00 & \pm 2.00 \\
Coolant temperature at core outlet \#2, K & 545.00 & \pm 2.00 \\
Coolant temperature at core outlet \#3, K & 544.90 & \pm 2.00 \\
Coolant temperature at core outlet \#4, K & 545.00 & \pm 2.00 \\
Mass flow rate of loop \#1, kg/s & 4737 & \pm 110 \\
Mass flow rate of loop \#2, kg/s & 4718 & \pm 110 \\
Mass flow rate of loop \#3, kg/s & 4682 & \pm 110 \\
Mass flow rate of loop \#4, kg/s & 4834 & \pm 110 \\
\hline
\end{tabular}

header pressure amounts to $5.07 \mathrm{MPa}$, meaning $1.0 \mathrm{MPa}$ lower than the nominal value.

5.1.2. Test Phase. The test was performed in 1991 at the Kozloduy NPP [6]. It was initiated by the isolation of the steam generator of loop 1 due to the closure of the main steam isolation valve. As a consequence, the primary coolant temperature of loop 1 started to increase up to about $14 \mathrm{~K}$ higher than the coolant temperature of the other loops. Under such conditions, coolant mixing occurred, first of all in the downcomer region. The resulting mixing pattern propagates through the lower plenum, core, and upper plenum. Since the power was relatively low, the feedbacks between thermal hydraulics and core neutronics are negligible according to the recorded data. Due to the mixing, the temperature of the unaffected loops especially of the loop close to the loop 1 (loop 2) increased. The test lasted for 1800 seconds. At that time the power increased up to $286 \mathrm{MW}$. Different data were recorded at the Kozloduy plant during the test. The coolant temperature at the cold/hot legs was measured with one thermal resistor at the level of pipe axis and two thermocouples in the lower part of the flow section. At some fuel assembly positions the coolant temperature at the core outlet was also measured. Fuel outlet temperatures and experimentally determined mixing coefficients from cold legs to fuel assembly outlets were also measured for the qualification of CFD codes. From this data, the fuel assembly inlet temperatures were derived, assuming that the relative temperature rise distribution does not change during the transient.

In Figure 13, the recorded data of the four hot legs are given for the whole test, that is, 1800 seconds. There it can be seen that the coolant temperature of the affected loop 1 starts to increase very rapidly at around 130 seconds due to the deteriorated heat transfer over the SG 1. From 500 seconds onward the increasing rate becomes smaller, stabilizing at a value below $556 \mathrm{~K}$. Due to the coolant mixing in the downcomer the temperature of the loop 2 experienced

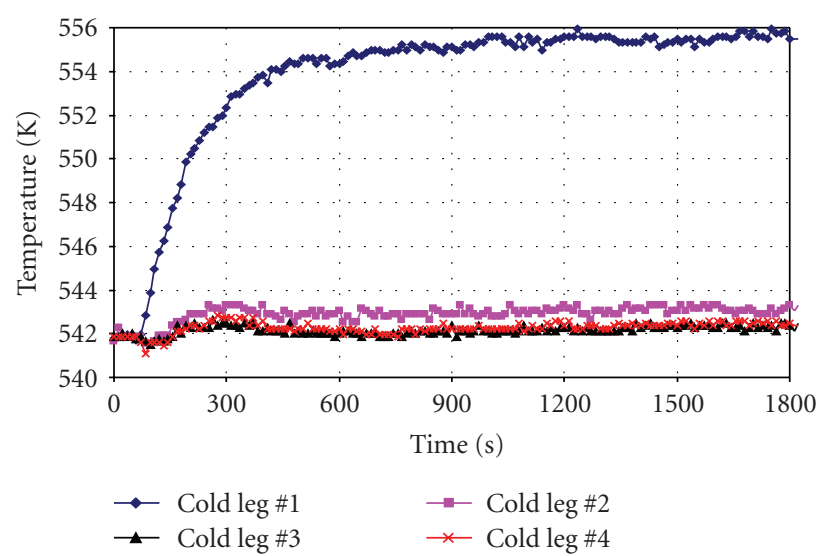

FIgURE 13: Measured evolution of the hot legs during the test at the KNPP.

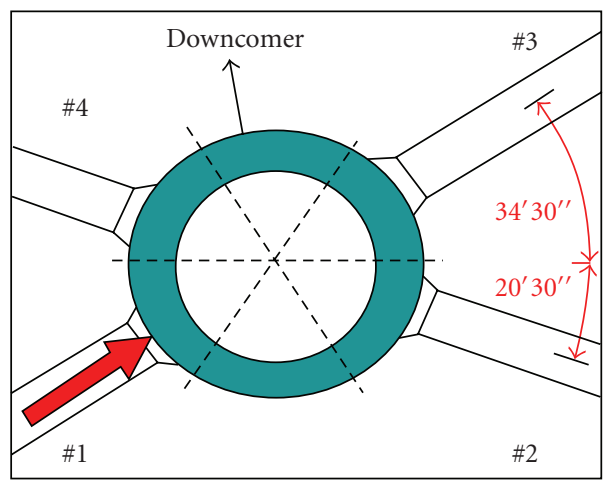

FIgURE 14: Location of the loops with respect to the downcomer.

a higher temperature than the one of loop 4, indicating that the mixing pattern is not in clockwise direction. Note that the position of the loops is not symmetrical (Figure 14). The core parameters at the end of the test (at 1800 seconds) are given in Table 5.

5.2. Selected TRACE Results. The TRACE posttest calculations of the coolant mixing experiment were performed in two steps. First of all, a steady-state calculation was carried out to predict the plant conditions just before the test. Secondly, a transient run was made for 1800 seconds to determine the final state of the plant. The time dependent boundary conditions, for example, loops flow rate, coolant temperature of the cold legs, and the system pressure were defined in the benchmark specifications [6].

5.2.1. Prediction of the Initial Plant State. In Table 3, a comparison of the TRACE predictions and the plant data is given for the initial plant state to be exhibit. It can be seen that the agreement between data and prediction is quite good. At the initial state the coolant temperature at the core inlet/outlet is uniformly since all pumps and steam generators are in operation. This will change drastically during the heat-up test progression. Note that the largest deviation between the prediction and the data is below $4 \%$. 
TABLE 3: Comparison of TRACE predictions with plant data for the initial state.

\begin{tabular}{|c|c|c|c|c|}
\hline Parameter & Initial state & Accuracy & TRACE & Deviation \\
\hline Thermal power, MW & 281 & \pm 60 & 281 & 0 \\
\hline Pressure above core, $\mathrm{MPa}$ & 15.593 & \pm 0.300 & 15.592 & 0.001 \\
\hline Pressure drop over RPV, MPa & 0.418 & \pm 0.043 & 0.404 & 0.014 \\
\hline Coolant temperature at core inlet $\# 1, \mathrm{~K}$ & 541.75 & \pm 1.50 & 541.78 & -0.03 \\
\hline Coolant temperature at core inlet \#2, $\mathrm{K}$ & 541.85 & \pm 1.50 & 541.88 & -0.03 \\
\hline Coolant temperature at core inlet \#3, K & 541.75 & \pm 1.50 & 541.78 & -0.03 \\
\hline Coolant temperature at core inlet \#4, $\mathrm{K}$ & 541.75 & \pm 1.50 & 541.78 & -0.03 \\
\hline Coolant temperature at core outlet \#1, K & 545.00 & \pm 2.00 & 544.63 & 0.37 \\
\hline Coolant temperature at core outlet \#2, $\mathrm{K}$ & 545.00 & \pm 2.00 & 544.70 & 0.30 \\
\hline Coolant temperature at core outlet $\# 3, \mathrm{~K}$ & 544.90 & \pm 2.00 & 544.61 & 0.29 \\
\hline Coolant temperature at core outlet $\# 4, \mathrm{~K}$ & 545.00 & \pm 2.00 & 544.62 & 0.38 \\
\hline Mass flow rate of loop $\# 1, \mathrm{~kg} / \mathrm{s}$ & 4737 & \pm 110 & 4749 & -12 \\
\hline Mass flow rate of loop $\# 2, \mathrm{~kg} / \mathrm{s}$ & 4718 & \pm 110 & 4735 & -17 \\
\hline Mass flow rate of loop \#3, kg/s & 4682 & \pm 110 & 4750 & -68 \\
\hline Mass flow rate of loop $\# 4, \mathrm{~kg} / \mathrm{s}$ & 4834 & \pm 110 & 4737 & 97 \\
\hline
\end{tabular}

5.2.2. Predicted Final Plant State. The transient phase started with the isolation of the main steam isolation valve and lasted for 1800 seconds. The final plant state predicted by TRACE is compared to the plant data and shown in Table 4. There, it can be observed that the code predictions are close to the plant data. In addition to the hot/cold leg temperatures, the pressure drop is also in good agreement with the data. Since during the test the hot leg temperature of the loop 1 (Figure 13) was continuously increasing while the one of the other loops were not, a considerable coolant mixing took place in the downcomer. The predicted temperatures in the six sectors of the downcomer are shown in Figure 15. The increase of the temperature in sector two and three was due to the mixing process. It is worth to mention that the mixing took place in counter clockwise direction.

The predicted coolant temperature of each fuel assembly at the core outlet for the beginning and end state of the test is given in Figures 15, 16, and 17. In Figure 17 the mixing pattern within the core can be observed. The hotter fluid of the loop 1 get mixed with the one of the sector between the loop 1 and loop 2, that is, in counter-clockwise direction as observed in the tests.

A comparison of the measured coolant temperature at the fuel assembly outlet with the predicted values by TRACE is given in Figure 18. It can be seen that the TRACE predictions follow qualitatively the trend of the measured data. In some positions, TRACE tends to over predict and in others to under predict the data. But the differences between data and predictions are within the measurement error. These trends are comparable to the trends predicted by CFX-5 [12].

5.3. Performed RELAP5/CFX Simulations. In this offline coupling approach, the CFX calculations [12] were performed first taking into account the initial and boundary conditions at the vessel inlet (cold legs1 to 4). From these investigations, the detailed flow conditions at the core inlet for each fuel

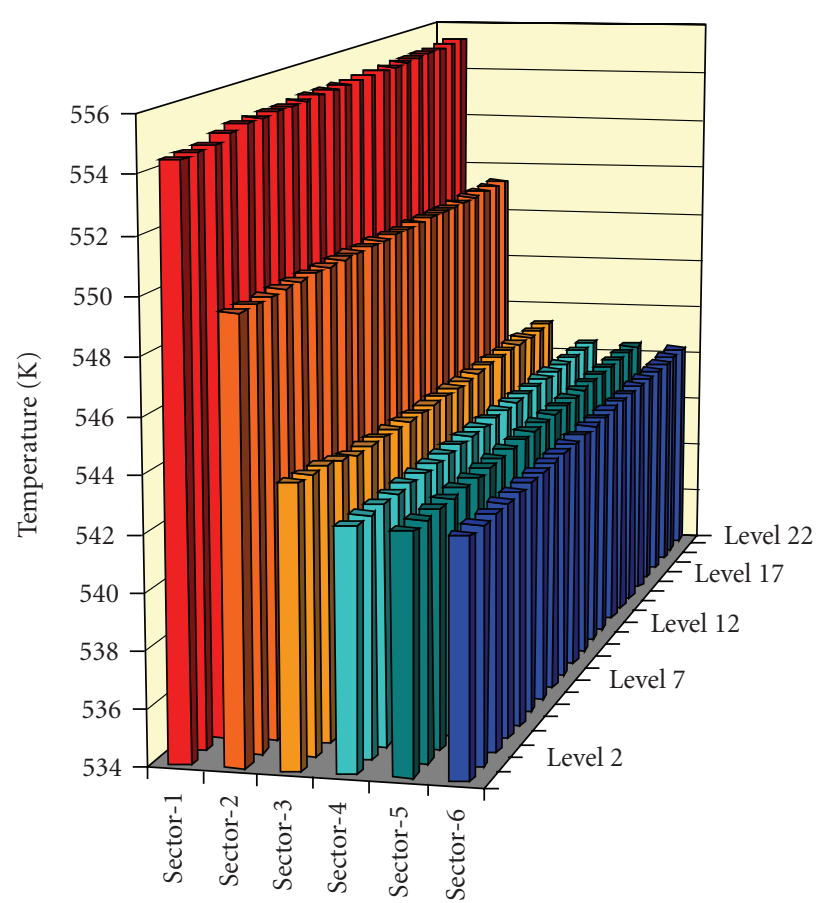

FIGURE 15: Predicted coolant temperature in the sectors of the downcomer (levels: 2 to 22 ).

assembly (RELAP5 PIPE component) like coolant temperature, mass flow rate, were derived as time dependent tables for the RELAP5 simulation [11]. Afterwards, these tables were used in the detailed whole core model of RELAP5 as time dependent boundary conditions. By this way, the RPV behavior could be analyzed in a more detailed sense as it can be done if only a whole 1D model of the RPV for RELAP5 is used. The focus here was to explore the possible way of combination of CFX and system codes for dedicated 
TABLE 4: Comparison of TRACE predictions with plant data for the final state.

\begin{tabular}{|c|c|c|c|c|}
\hline Parameter & Final state & Accuracy & TRACE & Deviation \\
\hline Thermal power, MW & 286 & \pm 60 & 286 & 0.000 \\
\hline Pressure above core, $\mathrm{MPa}$ & 15.593 & \pm 0.300 & 15.591 & 0.002 \\
\hline Pressure drop over RPV, MPa & 0.417 & \pm 0.043 & 0.404 & 0.013 \\
\hline Coolant temperature at core inlet \#1, K & 555.35 & \pm 1.50 & 555.39 & -0.04 \\
\hline Coolant temperature at core inlet \#2, $\mathrm{K}$ & 543.05 & \pm 1.50 & 543.08 & -0.03 \\
\hline Coolant temperature at core inlet \#3, K & 542.15 & \pm 1.50 & 542.18 & -0.03 \\
\hline Coolant temperature at core inlet \#4, $\mathrm{K}$ & 542.35 & \pm 1.50 & 542.38 & -0.03 \\
\hline Coolant temperature at core outlet \#1, K & 554.85 & \pm 2.00 & 555.14 & -0.29 \\
\hline Coolant temperature at core outlet \#2, $\mathrm{K}$ & 548.55 & \pm 2.00 & 548.66 & -0.11 \\
\hline Coolant temperature at core outlet $\# 3, \mathrm{~K}$ & 545.75 & \pm 2.00 & 545.44 & 0.31 \\
\hline Coolant temperature at core outlet $\# 4, \mathrm{~K}$ & 546.45 & \pm 2.00 & 545.69 & 0.76 \\
\hline Mass flow rate of loop $\# 1, \mathrm{~kg} / \mathrm{s}$ & 4566 & \pm 110 & 4657 & -91 \\
\hline Mass flow rate of loop \#2, kg/s & 4676 & \pm 110 & 4693 & -17 \\
\hline Mass flow rate of loop \#3, kg/s & 4669 & \pm 110 & 4724 & -55 \\
\hline Mass flow rate of loop $\# 4, \mathrm{~kg} / \mathrm{s}$ & 4816 & \pm 110 & 4724 & 92 \\
\hline
\end{tabular}

TABLe 5: Main parameters of the NPP at the end of the test (1800 seconds).

\begin{tabular}{lcc}
\hline Parameter & Final state & Accuracy \\
\hline Thermal power, MW & 286 & \pm 60 \\
Pressure above core, MPa & 15.593 & \pm 0.300 \\
Pressure drop over RPV, MPa & 0.417 & \pm 0.043 \\
Coolant temperature at core inlet \#1, K & 555.35 & \pm 1.50 \\
Coolant temperature at core inlet \#2, K & 543.05 & \pm 1.50 \\
Coolant temperature at core inlet \#3, K & 542.15 & \pm 1.50 \\
Coolant temperature at core inlet \#4, K & 542.35 & \pm 1.50 \\
Coolant temperature at core outlet \#1, K & 554.85 & \pm 2.00 \\
Coolant temperature at core outlet \#2, K & 548.55 & \pm 2.00 \\
Coolant temperature at core outlet \#3, K & 545.75 & \pm 2.00 \\
Coolant temperature at core outlet \#4, K & 546.45 & \pm 2.00 \\
Mass flow rate of loop \#1, kg/s & 4566 & \pm 110 \\
Mass flow rate of loop \#2, kg/s & 4676 & \pm 110 \\
Mass flow rate of loop \#3, kg/s & 4669 & \pm 110 \\
Mass flow rate of loop \#4, kg/s & 4816 & \pm 110 \\
\hline
\end{tabular}

applications. Hereafter, the transient evolution of the hot loop temperatures predicted by TRACE and RELA5/CFX, in comparison with measured data, will be presented and discussed.

5.4. Comparison of TRACE and RELAP5/CFX Transient Results. Different parameters of the Kozloduy plant were measured during the test like the hot leg temperatures at the RPV outlet. Time dependent data were derived from these measurements. These data are compared in Figures 19, 20, 21 , and 22 .

In these figures, it can be seen that the predictions of TRACE and RELAP5/CFX are in very good agreement with the experimental data. The temperature evolution of all loops shows a mixing effect that starts in the downcomer

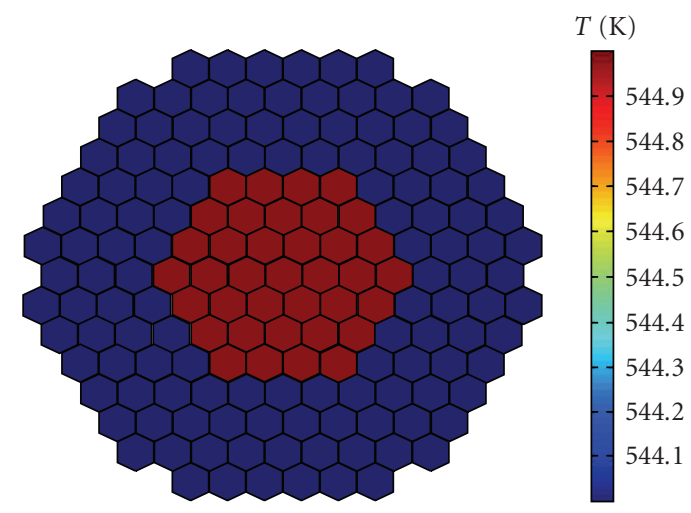

Figure 16: Predicted coolant temperature at the core outlet at initial state ( 0 second).

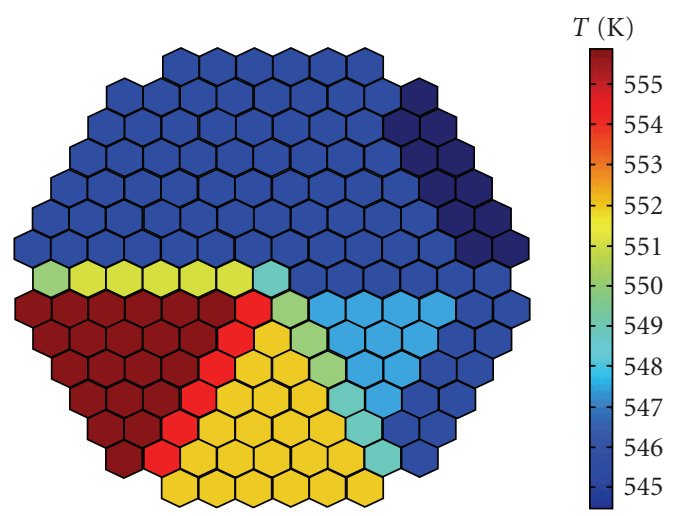

FIGURE 17: Predicted coolant temperature at core outlet at final state (1800 seconds).

and propagates through the core to the upper plenum since all pumps are running and high coolant velocities prevail during the transient. Apparently, this is not the case for loop 2. But reevaluation [13] of this experiment performed 


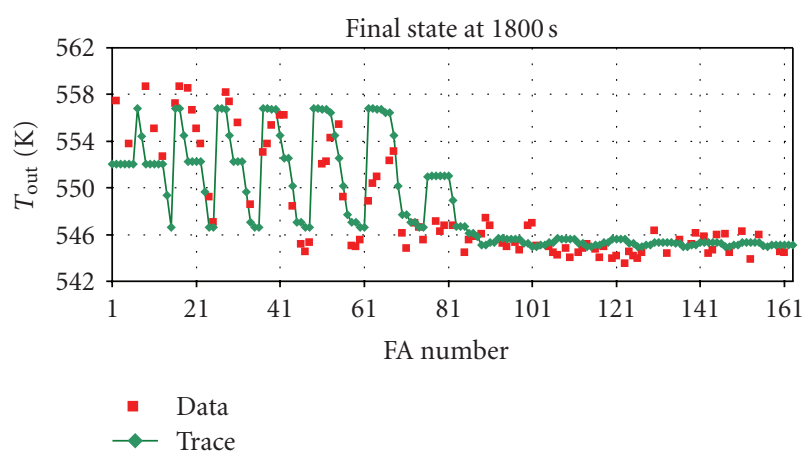

FIGURE 18: Comparison of the predicted coolant temperature at each FA outlet with data.

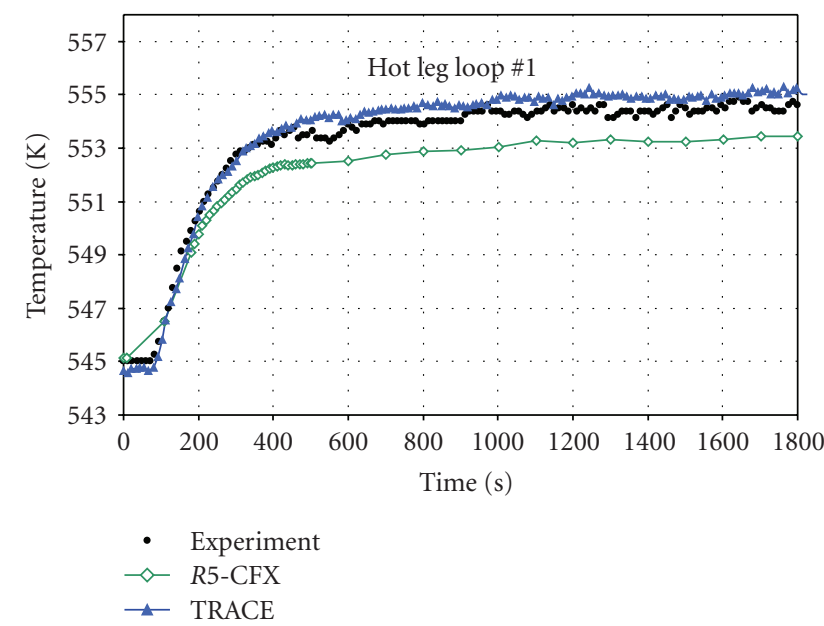

FIgURe 19: Comparison of the data with the predictions for loop 1.

by the benchmark team leads to the conclusion that the measured value for loop 2 should be around $548 \mathrm{~K}$ instead of $545 \mathrm{~K}$. Only for loop 1 the TRACE results are closer to the data compared to the RELAP5/CFX ones. But for the other loops the RELAP5/CFX results are in better agreement with the data, which is expected since the coolant mixing is better described by CFD tools than by coarse mesh 3D thermal hydraulic codes such as TRACE.

\section{Conclusions and Further Work}

In this paper, investigations performed to validate the 3D thermal hydraulic model of TRACE based on plant data (Kozloduy nuclear power plant) were presented and discussed. Detailed models for a 3D coarse mesh system code (TRACE) and for RELAP5/CFX were developed for the analysis of the heap-up test, where the coolant mixing within the RPV was the dominating process. The constructive peculiarities of the RPV, important for the elaboration of the 3D models, are also outlined. Although the azimuthal subdivision of the 3D reactor pressure level consists of only six sectors, this model is useful for global comparison of coolant temperatures at the hot legs against data and RELAP5/CFX simulations.

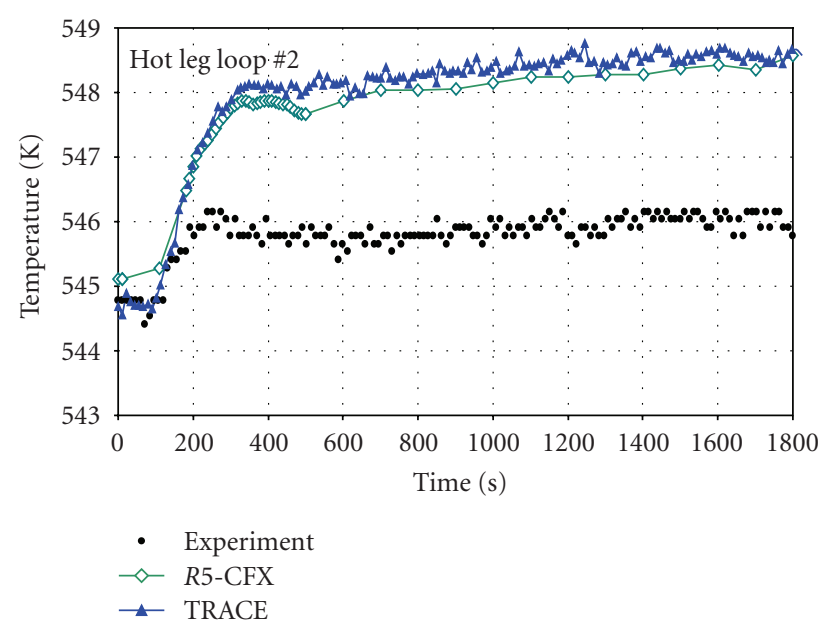

Figure 20: Comparison of the data with the predictions for loop 2.

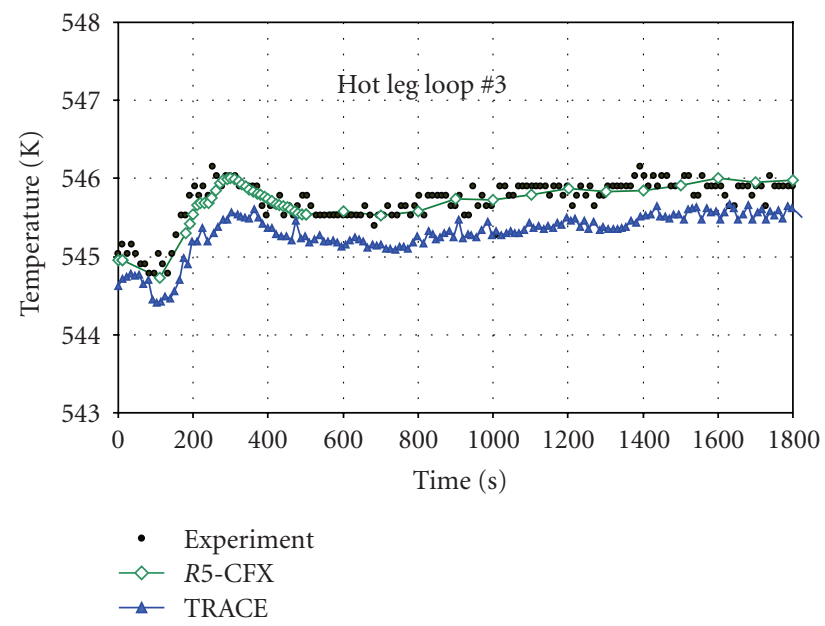

FIGURE 21: Comparison of the data with the predictions for loop 3.

From the comparison of the calculated parameters by TRACE with the available measurement data the following conclusions can be drawn.

(i) The initial plant conditions just predicted by TRACE are in a very good agreement with the plant data.

(ii) The final plant state predicted by TRACE is close to the plant data and the deviations are within the measurement error band.

(iii) The evolution of important plant parameter, predicted by TRACE, follows nicely the measured trends, indicating that the mixing within the RPV is well described by the simulations (hot leg temperature of all loops).

(iv) A detailed comparison of the calculated coolant temperature at the core outlet for each fuel assembly position with available data showed good trends.

(v) TRACE was also able to predict the counter-clockwise rotation, that is, the mixing preferably in direction of loops 2 and 3 instead of loop 4. 


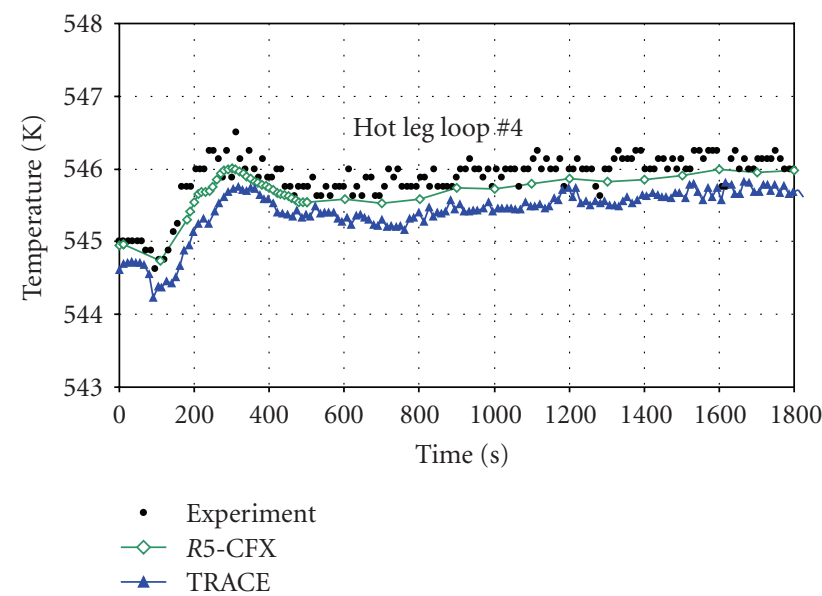

Figure 22: Comparison of the data with the predictions for loop 4.

In general, it can be stated that the chosen $3 \mathrm{D}$ thermal hydraulic nodalization scheme using the VESSEL component of TRACE seems to be appropriate to catch the underling physics of the coolant mixing process of VVER-1000 reactors.

These results are very encouraging and they underline the capability of the 3D VESSEL component of TRACE, which is very flexible, allowing simulations ranging from $1 \mathrm{D}$ over $2 \mathrm{D}$ to $3 \mathrm{D}$. Consequently, the validated 3D model of the RPV of the VVER-1000 reactor can be used to investigate transients where the coolant mixing is a key issue such as deboration, main steam line break, and so forth.

The performed investigations, to assess the capability of the offline coupling RELAP5/CFX, have shown the potential of such coupling and the need for the development of more sophisticated multiscale coupling schemes for system codes and CFD codes. The combination of RELAP5 with CFX improved the quality of the obtained results for the coolant mixing phenomena of VVER-1000 reactors. The developed models regard the constructive and design peculiarities of this reactor type, and hence, it cannot be applied for another reactor design.

Additional refinement of the 3D vessel TRACE model will be done to perform detailed comparison of the TRACE predictions with the available data at a local, more detailed, spatial level in the downcomer, core entrance, and core outlet. The obtained results with the six azimuthal sectors are encouraging the extension of this model to at least 12 azimuthal sectors to really catch the physical phenomena measured in the heat-up test.

\section{List of Acronyms}

ATHLET: Analysis of thermal-hydraulics of leaks and transients

ATWS: Anticipated transients without scram

BWR: Boiling water reactor

BOC: $\quad$ Begin of cycle
CATHARE: Code for analysis of thermal-hydraulics during an accident of reactor and safety evaluation

CFD: $\quad$ Computational fluid dynamics

EFPD: $\quad$ Effective full power days

INR: Institute of Neutron Physics and Reactor Technology

KNPP: $\quad$ Kozlody nuclear power plant

LANL: Los Alamos National Laboratory

MSLB: $\quad$ Main steam line break

PARCS: Purdue advanced reactor core simulator

PWR: $\quad$ Pressurized water reactor

RELAP: Reactor excursion and leak analysis program

RPV: $\quad$ Reactor pressure vessel

SG: $\quad$ Steam generator

SNAP: $\quad$ Symbolic nuclear analysis package

TRACE: TRAC/RELAP advanced computational engine

TRAC: $\quad$ Transient reactor analysis code

VVER: Water-water energy reactor.

\section{References}

[1] R. Riemke, "RELAP5 multi-dimensional constitutive models," in RELAP5/TRAC-B International Users Seminar, Baton Rouge, La, USA, November 1991.

[2] "TRAC-BF/MOD1: An advanced best-estimate computer program for BWR accident analysis," US Nuclear Regulatory Commission Report NUREG/CR-4356-Vol.1, Idaho National Engineering Laboratory, August 1992.

[3] P. Bazin and M. Pelissier, "CATHARE 2 V25_1: description of the base revision 6.1 physical laws used in the $1 \mathrm{D}, 0 \mathrm{D}$ and $3 \mathrm{D}$ modules," CEA/DER/SSTH/LDAS/EM/2005-038, 2006.

[4] U. Graf, "Implicit coupling of fluid-dynamic systems: application to multidimensional counter-current two-phase flow of water and steam," Nuclear Science and Engineering, vol. 129, no. 3, pp. 305-310, 1998.

[5] F. Odar, et al., “TRACE V4.0 User's Manual,” US NRC, 2005.

[6] N. Kolev, S. Aniel, E. Royer, U. Bieder, D. Popov, and Ts. Topalov, "The OECD VVER-1000 Coolant Transient Benchmark Phase 2 (V1000CT-2) Volume I: Specifications of the Coolant mixing problem," NEA/NC DOC, 2004.

[7] ANSYS Inc., “ANSYS CFX Release 11.0," Reference Guide, 2007.

[8] H. G. Joo, D. Barber, G. Jiang, and T. Downar, "PARCS: a multidimensional two-group reactor kinetics code based on the nonlinear analytical nodal method," School of Nuclear Engineering, Purdue University, July 2002.

[9] W. Jaeger, W. Lischke, and V. H. Sánchez Espinoza, "Safety related investigations of the VVER-1000 reactor type by the coupled code system TRACE/PARCS," in Proceedings 15th International Conference on Nuclear Engineering (ICONE '07), Nagoya, Japan, April 2007.

[10] V. Sánchez, et al., "Analysis of the VVER-1000 coolant transient benchmark phase 1 with RELAP5/PARCS," Progress of Nuclear Energy, vol. 48, pp. 865-879, 2006.

[11] B. Truong, "Application of RELAP5/PARCS coupled-code system in studying coolant mixing and main steam line break transients behavior of VVER-1000 reactor," Tech. Rep., FZK, August 2006. 
[12] M. Boettcher, "Investigations of the coolant mixing phenomena within reactor pressure vessel of the VVER-1000 reactor," Nuclear Engineering and Design, vol. 238, pp. 445-545, 2008.

[13] N. Kolev, et al., "Comparative analysis of exercise 2 results of the OECD VVER-1000 MSLB benchmark," in Proceedings of the 16th Symposium of AER on VVER Reactor Physics and Safety, Bratislava, Slovak Republic, September 2006. 

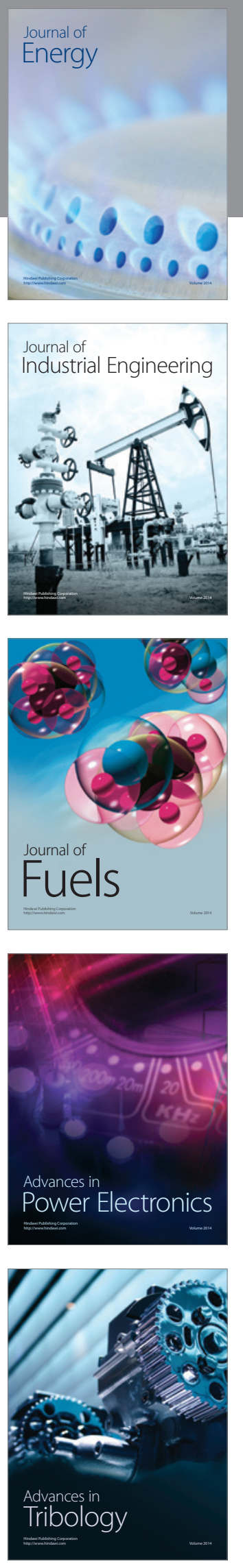
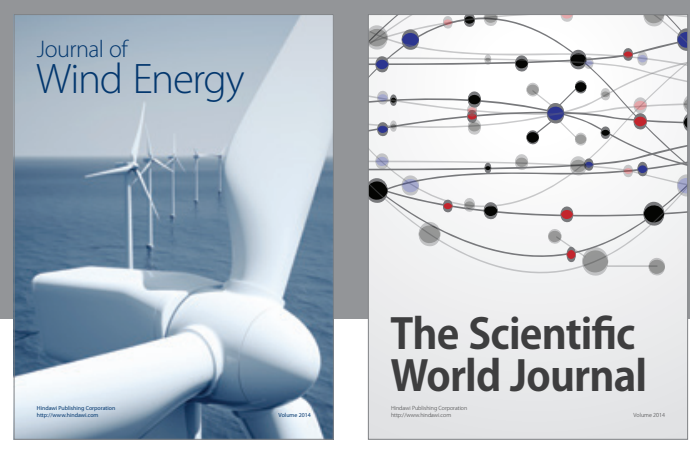

The Scientific World Journal

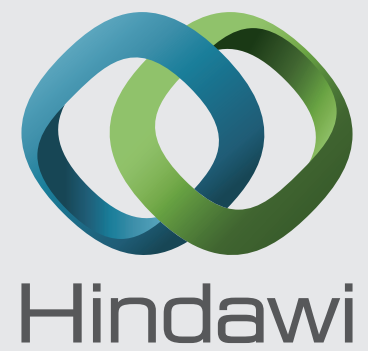

Submit your manuscripts at http://www.hindawi.com
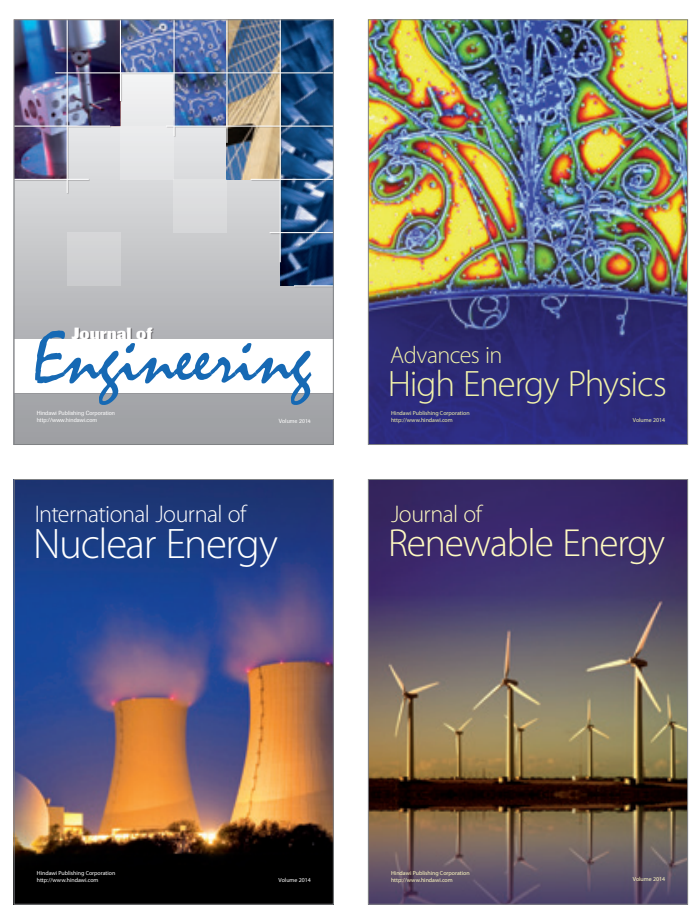

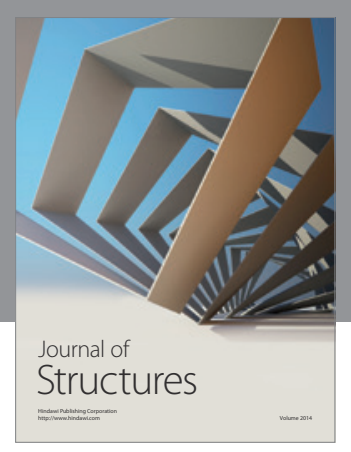

Rotating
Mechinery
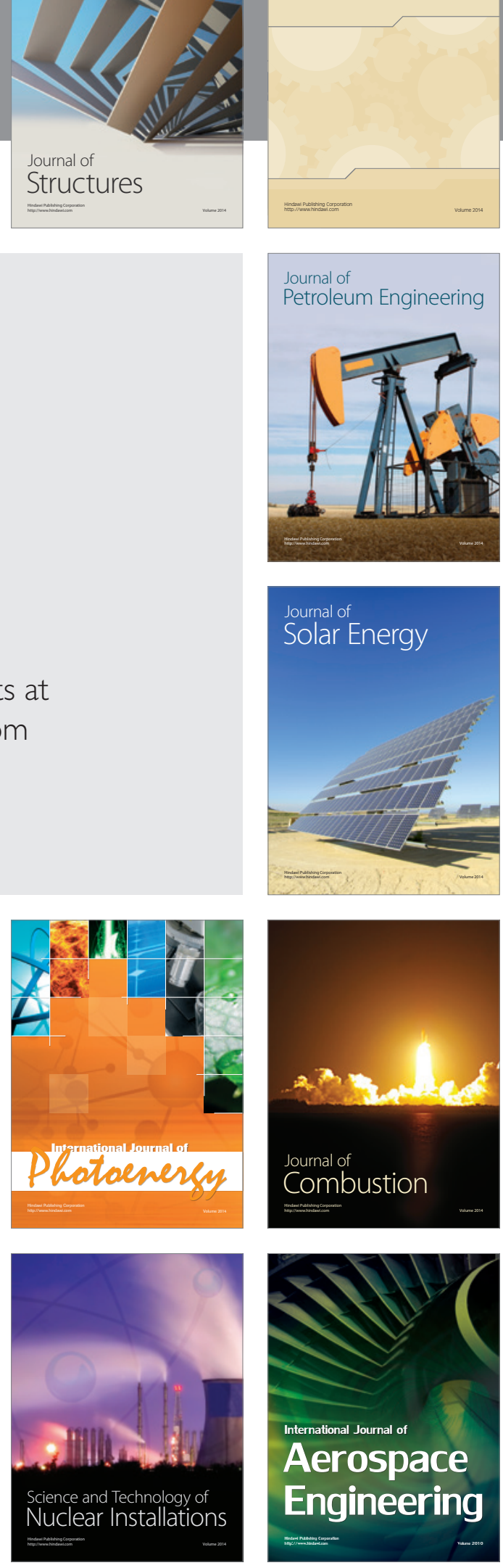